\title{
Correction to: Socio-economic resources and adult mental health in Canada: controlling for time-invariant confounders and investigating causal directionality
}

\author{
Adam Vanzella-Yang ${ }^{1} \cdot$ Gerry Veenstra $^{1}$ \\ Published online: 7 July 2021 \\ (C) The Canadian Public Health Association 2021
}

Correction to: Canadian Journal of Public Health. https://doi.org/10.17269/s41997-021-00547-y

Due to a production error, this article was updated to correct an entry in Table 1: minus sign inserted to read " -0.42 " in the "Postsecondary degree" line of the "Lagged (2012-2014)" section.

Publisher's note Springer Nature remains neutral with regard to jurisdictional claims in published maps and institutional affiliations.

The online version of the original article can be found at https://doi.org/ 10.17269/s41997-021-00547-y

Adam Vanzella-Yang

adamvy@mail.ubc.ca

11 Department of Sociology, University of British Columbia, 6303 N. W. Marine Drive, Vancouver, BC V6T 1Z1, Canada 